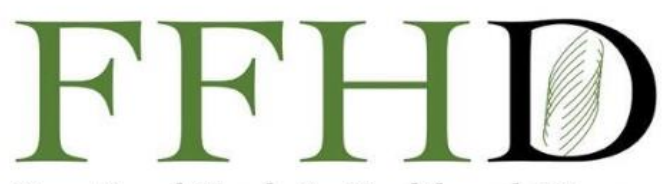

Functional Foods in Health and Disease

\title{
In vitro Alpha-amylase inhibition, antioxidant, nutritional and sensory properties of functional spice-blend fortified cookies
}

\author{
Gloria Aderonke Otunola*, Anthony Jide Afolayan
}

Medicinal Plants \& Economic Development (MPED) Research Centre, Department of Botany, University of Fort Hare, Alice 5700, South Africa

*Corresponding Author: Gloria Aderonke Otunola, PhD, Medicinal Plants \& Economic Development (MPED) Research Centre, Department of Botany, University of Fort Hare, Alice 5700, South Africa

Submission Date: September 21 ${ }^{\text {st }}, 2021$; Acceptance Date: October 22 ${ }^{\text {nd }}, 2021$; Publication Date: February $2^{\text {nd }}, 2022$

Please cite this article as: Otunola G.A., Afolayan A.J. In vitro Alpha-amylase inhibition, antioxidant, nutritional and sensory properties of functional spice-blend fortified cookies. Functional Foods in Health and Disease 2022; 12(2): 56-69. DOI: https://www.doi.org/10.31989/ffhd.v12i2.845

\section{ABSTRACT:}

Introduction: Fortification of foods is often performed to formulate and develop functional foods that improve the nutritional and health status of consumers.

Methods: In this study, a spice-blend (cayenne pepper, garlic and ginger) was incorporated into wheat flour at 5, 10, 15 and $20 \%$ for the production of nutritional and healthy cookies. Physicochemical, nutritional, sensory, total phenolics, antioxidant activity and alpha-amylase inhibitory assays of the cookies were performed and compared with control cookies and standards (vitamin $\mathrm{C}$ and acarbose ) respectively.

Results: Significant differences $(P<0.05)$ were observed in color, weight, diameter, height, and texture of the spice-blend cookies. Fat, ash, fiber, magnesium, potassium, sodium, phosphorous and manganese contents of the cookies were significantly improved, especially as the spice mix increased, while iron, calcium copper and zinc were stable. Sensory evaluation revealed a high acceptability of the spice-cookies at up to $5 \%$ fortification. Interestingly, although the total phenol and flavonoid content of the fortified cookies was low, the antioxidant activity was high compared to control cookies and competitively with vitamin C, the standard antioxidant used. Inhibitory activity of the fortified cookies against alpha-amylase was significant and dose responsive.

Conclusion: These results indicate that the spice blend at $5 \%$ addition has potential as a therapeutic healthy snack for 
the prevention of malnutrition and hyperglycemia in type 2 diabetes.

Keywords: cookies, functional foods, hyperglycemia, sensory, bioactive compounds

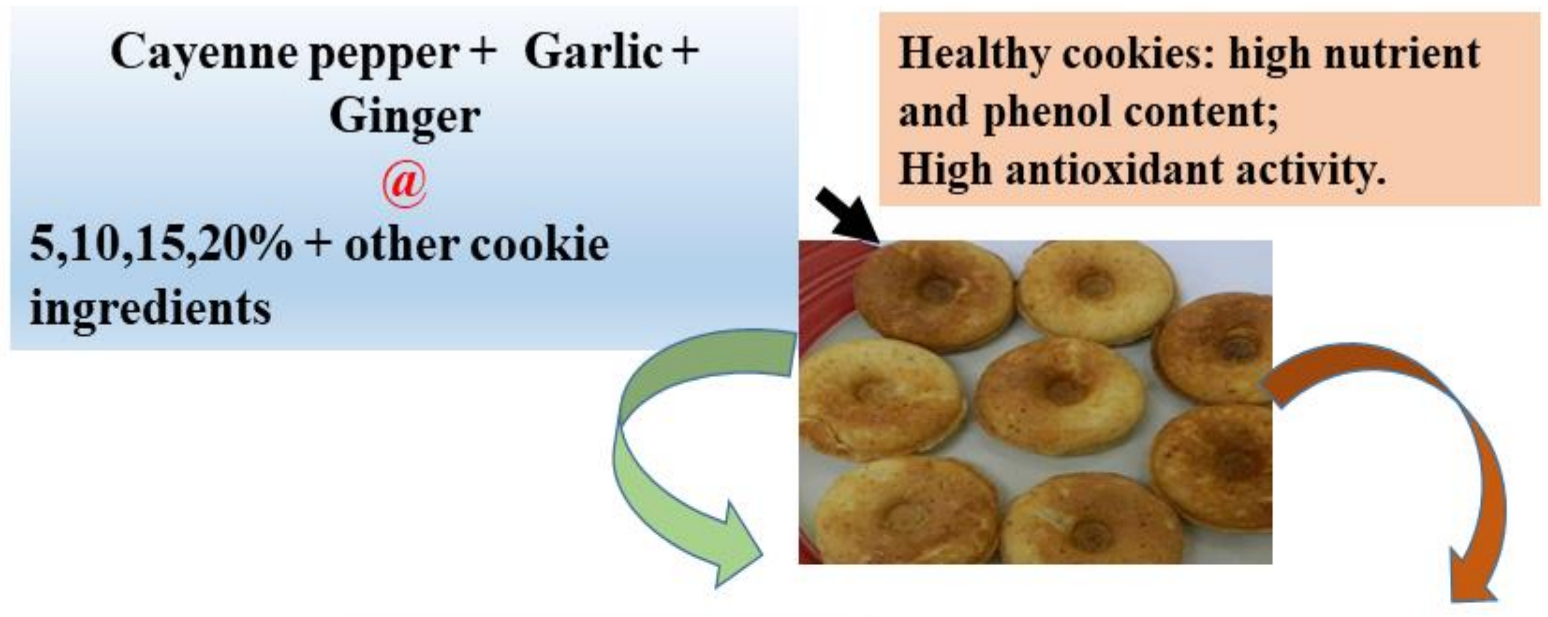

1. Dose-responsive increase in fat, ash and fiber contents of spice-blend cookies.

\section{Acceptability was best at $5 \%$ (MC1) spice- blend addition}

1. Higher dose-responsive antioxidant activities of spice-blend cookies.

\section{Alpha-amylase inhibition enhanced reduction in postpandrial glucose}

CFFC 2022. This is an Open Access article distributed under the terms of the Creative Commons Attribution 4.0 License (http://creativecommons.org/licenses/by/4.0)

\section{INTRODUCTION}

Cookies are baked products generally prepared using refined flour, sugar, hydrogenated fats, and some minor ingredients such as additives and emulsifiers [1]. Cookies represent the largest category of snack item among bakery products widely accepted by both young and old due to their affordable price, convenience, storability and nutritive values [2-3]. They are therefore very suitable as vehicle for introducing nutrients and phytomedicines. Spices and aromatic herbs have been used since ancient times as preservatives, colorants, flavor enhancers and are the basis of traditional medicine in many cultures. Research into the role of spices as contributors of dietary polyphenols, associated with reducing the risk of developing chronic non communicable diseases, is on the increase. The antioxidative, anti-diabetic, hypolipidemic, anti-bacterial, anti-inflammatory, anti-viral, anti-cancer and digestive activities of several spices have been demonstrated both in vitro and in vivo [4-7]. However, bearing in mind that spices are consumed normally in small quantities and in combination with other foods, it is unclear what their 
true benefit is from a health perspective and if their functionality is retained when cooked or processed.

Considerable interest has been expressed by manufacturers, consumers and health professionals in functional foods and nutraceuticals for obvious reasons including the fact that many patients are averse to the use of drugs and may accidentally or deliberately avoid taking their prescriptions. Consumption of food does not carry such an aversion; therefore, fortified foods could be an effective way to deliver beneficial agents aimed at reducing disease risk.

Alpha-amylase is one of the key human enzymes responsible for the breakdown of starch into simpler sugars. The inhibition of this enzyme can impede carbohydrate digestion and decrease postprandial glucose absorption [8].

Although garlic, ginger, cayenne pepper and a combination of the three spices have been shown to possess high polyphenolic content and antioxidant activities; and are effective in the treatment of hypercholesterolemia, oxidative stress and diabetes in a manner comparable with standard reference drugs, [910] no study of the use of the blend in the production of functional cookies has been performed.

Diabetes mellitus is an endocrine disorder characterized by chronic hyperglycemia, which affects humans as a result of defects in insulin secretion or resistance. People with diabetes on certain types of drugs or insulin are often advised not to eat snacks despite their cravings, because it is believed that snacking leads to increased postprandial glucose. In order to decrease postprandial hyperglycaemia in the management of diabetes, particularly type 2 diabetes, a promising approach is by inhibiting carbohydrate hydrolysing enzymes ( $\alpha$-amylase and $\alpha$-glucosidase) in the gastrointestinal tract [11]. Inhibition of these enzymes slow down carbohydrate digestion, prolong overall digestion time, thereby causing a reduction in postprandial glucose absorption [11].

Studies have reported that little changes in the diet, such as inclusion of morning and afternoon snacks of type-2 diabetes patients may promote body weight and fat-mass loss, as well as help in maintaining blood glucose balances [12-13]. It is important therefore, to develop healthy snacks that could support the management of hyperglycemia and diabetes without compromising nutrition.

Hence, this study evaluated the physical, nutritional, sensory and biological functions of cookies fortified with a blend of garlic, ginger and cayenne spices.

\section{METHODS}

Reagents and materials: All reagents and chemicals were sourced from Sigma-Aldrich (South Africa) and were of the highest analytical grade. The flour, spices, butter, eggs, sugar and salt were purchased at the local supermarket in Alice, Eastern Cape, South Africa.

Preparation of spice blend: Garlic, ginger and pepper were purchased from the local grocery shop in Alice, Eastern Cape, South Africa. The spices were cleaned separately, thinly sliced, dried in an oven at $50^{\circ} \mathrm{C}$ for 72 $\mathrm{h}$ then homogenized. Weights of each spice in the ratio 1:0.5:0.25 (ginger: garlic: cayenne pepper) respectively, were passed through a coffee grinder to give a homogeneous blend. This was stored at $4^{\circ} \mathrm{C}$ till needed.

Preparation of cookies: Five different types of cookies were formulated by substituting wheat flour with 0,5 , 10, 15 and 20\% (w/w) spice blend respectively. The ingredients used for the formulations of cookies are presented in Table 1. 
Table 1: Formulations for the preparation of spice-blend cookies

\begin{tabular}{|l|l|l|l|l|l|}
\hline Ingredients (g) & Control & MC1 & MC2 & MC3 \\
\hline Flour & 300 & 285 & 270 & 255 & 240 \\
\hline Sugar & 100 & 100 & 100 & 100 & 100 \\
\hline Margarine & 100 & 100 & 100 & 100 & 100 \\
\hline Egg & 60 & 60 & 60 & 60 & 60 \\
\hline Baking powder & 10 & 10 & 10 & 10 & 10 \\
\hline Milk (mL) & 150 & 150 & 150 & 150 & 150 \\
\hline Spice Blend & 0 & 15 & 30 & 45 & 60 \\
\hline
\end{tabular}

The ingredients were mixed to form dough, which was rolled on a cookie sheet and cut with a cookie cutter. Cookies were baked (each type in three replicates) at $150 \stackrel{\circ}{\mathrm{C}}$ for $20 \mathrm{~min}$ until golden brown. Following fiveminutes setting period, cookies were allowed to cool on wire racks for one hour after which sensory analyses were performed.

\section{Determination of Physical Properties of Cookies:}

Weight of cookies was measured as average values of four individual cookies from each replicate using an electronic weighing balance. Diameter (D) and Thickness (T) were determined using vernier callipers, while Spread ratio was expressed as diameter/thickness (D/T) [14]. The average values of 3 replicate determinations were reported.

Sensory evaluation: The cookies were evaluated for sensory attributes by a panel of 26 untrained volunteers familiar with the quality attributes of cookies, recruited among staff and students of the Faculty of Science and Agriculture, University of Fort Hare, South Africa. Each panellist evaluated all the samples prepared for each treatment in one session. The samples were presented to panellists in codes of three-digit combination letters and numbers. Appearance/color, flavor, texture, taste/crispness and overall acceptability of cookies were assessed using a nine-point Hedonic scale where 9=Like extremely; 8=Like very much; 7=Like moderately; 6=Like slightly; 5=Neither like nor dislike; 4=Dislike slightly; 3=Dislike moderately; 2=Dislike very much; and 1 $=$ Dislike extremely. The panellists were supplied with drinking water to rinse their mouths after evaluating each sample and were also asked to comment freely on the samples.

Proximate analysis: All the samples were analysed for moisture, ash, protein, fat and crude fiber using the AGRILASA [15] and the AOAC [16] methods. Total carbohydrate was calculated as: 100-(\% Moisture content $+\%$ Total Ash $+\%$ crude fat $+\%$ crude fiber $+\%$ crude protein).

Elemental analysis: All elemental analysis were performed using Inductively Coupled Plasma-Optical Emission Spectrometer (ICP-OES). Briefly, $0.3 \mathrm{~g}$ of the ground samples were weighed into dry, clean digestion tubes, $2.5 \mathrm{~mL}$ of digestion mixture (selenium powder, sulphuric acid and salicylic acid) was added to each tube and allowed to react at room temperature for $2 \mathrm{~h}$. The tubes were then heated on a block digester at $110^{\circ} \mathrm{C}$ for $60 \mathrm{~min}$, removed from the digester, allowed to cool, then $1 \mathrm{ml}$ portions of hydrogen peroxide added three times, allowing at least $10 \mathrm{~s}$ between additions. The tubes were returned to the block digester at a temperature of $330^{\circ} \mathrm{C}$ and digested until colorless, cooled to room temperature; their contents transferred into $50 \mathrm{~mL}$ volumetric flasks and de-ionized water added to attain $50 \mathrm{~mL}$. Standards were prepared for all the 
elements, each sample was then analyzed for the various elements in an ICP-OES (Varian 710-ES series, SMM Instruments, Cape Town, South Africa). The results were expressed as $\mathrm{mg} / 100 \mathrm{~g}$ dry weight (DW).

Energy content: The gross energy values were estimated by multiplying the values of crude protein, fat and carbohydrate by their respective Atwater factor:

Energy value $(\mathrm{kcal} / 100 \mathrm{~g})=($ crude protein $\times 4)+($ crude lipid $\times 9)+($ total carbohydrate $\times 4)$.

\section{Total Phenol Content (TPC) and antioxidant assays: The} powdered cookies $(5 \mathrm{~g})$ samples were extracted in 100 $\mathrm{mL}$ of water by gentle shaking on an orbital shaker for 1 hour, filtered then freeze-dried. TPC, antioxidant (DPPH and $A B T S$ ) and $\alpha$-amylase activities of the cookies were determined using the lyophilized samples.

Total Phenolic content was determined using the Folin-Ciocalteu assay as previously described [17] with tannic acid as standard. Briefly, in a 96-well microtiter plate, $10 \mu \mathrm{L}$ of the cookie extracts $(1 \mathrm{mg} / \mathrm{mL})$, tannic acid solutions of different concentrations $(2-10 \mu \mathrm{g} / \mathrm{mL})$ or water (blank) was mixed with $190 \mu \mathrm{L}$ of distilled water in each well. After this, $25 \mu \mathrm{L}$ of freshly prepared FolinCiocalteu reagent was added, allowed to stand for five minutes, then $75 \mu \mathrm{L}$ of $7.5 \% \mathrm{Na}_{2} \mathrm{CO}_{3}$ was added, gently vortexed and incubated at $60{ }^{\circ} \mathrm{C}$ for $10 \mathrm{~min}$, the absorbance was measured at $765 \mathrm{~nm}$ in a microplate reader. Different concentrations $(2-10 \mu \mathrm{g} / \mathrm{ml})$, of tannic acid in distilled water was used for preparation of the standard calibration curve. TPC was calculated using the equation derived from the calibration curve:

$$
Y=0.0043 x, \mathrm{R}^{2}=0.9919,
$$

where $Y$ is the absorbance and $x$ the tannic acid equivalent $(\mu \mathrm{g} / \mathrm{ml})$; and the results expressed in micrograms tannic acid equivalents per $100 \mathrm{~g}$ (ug $\mathrm{TAE} / 100 \mathrm{~g}$ ) of the cookies.

\section{2,2-diphenyl-1-picrylhydrazyl $\left(\mathrm{DPPH}^{+}\right)$radical} scavenging capacity DPPH radical scavenging was determined by the modified method of CarmonaJiménez [18]. Briefly, $10 \mu \mathrm{L}$ of the cookies extracts (0.05 $\mathrm{mg} / \mathrm{ml}$ ) or Vitamin C (standard/positive control) at different concentrations $(31.25,62.5,125,250,500$, and $1000 \mu \mathrm{L}$ ) and $50 \mu \mathrm{L}$ distilled water was added to $190 \mu \mathrm{L}$ of DPPH solution (0.1 mM in methanol) in a 96-well microtiter plate. The mixture was gently agitated, then incubated in the dark for $30 \mathrm{~min}$ at $25 \stackrel{\circ}{\circ}$, after which the absorbance (absorbance decreases with an increase in DPPH radical scavenging activity) was measured at $517 \mathrm{~nm}$ in a microplate reader. Each test was performed in triplicates and DPPH radical scavenging ability of the cookies extracts was calculated as:

$\mathrm{DPPH}^{+}$scavenging activity $(\%)=[($ Abs control-Abssample $) / \mathrm{Abs}$ control] $\times 100$

Where Abs control is the absorbance of DPPH radical + methanol without sample; and Abs sample is the absorbance of DPPH+ sample extract or standard. The antioxidant activity was expressed as $\mathrm{IC}_{50}(\mu \mathrm{g} / \mathrm{mL})$, the concentrations of sample that causes a $50 \%$ decrease of the absorbance at $517 \mathrm{~nm}$. A lower $\mathrm{IC}_{50}$ corresponds to a higher antioxidant activity.

\section{2,2-azinobis-3-ethylbenzo-thiazoline-6-sulfonate}

radical $\left(\mathrm{ABTS}^{+}\right)$Radical Scavenging Assay was determined using the method described by Thaipong et al. [19] was slightly modified. Briefly, stock solutions of 7 $\mathrm{mM}$ ABTS and $2.45 \mathrm{mM}$ potassium persulfate solutions were prepared, mixed in the ratio $(1: 1 ; \mathrm{v} / \mathrm{v})$ and stored for $12 \mathrm{~h}$ at room temperature in the dark, during which period $A B T S$ radical was generated. The solution was then diluted with methanol to an absorbance of $0.708 \pm$ 0.001 at $734 \mathrm{~nm}$. An aliquot, $25 \mu \mathrm{L}$ of the cookie extracts or standard antioxidant (vitamin C), $225 \mu \mathrm{L}$ ABTS $^{*+}$ working solution was added and allowed to react for 6 $\min$ at $25 \stackrel{\circ}{ } \mathrm{C}$ after which the absorbance was measured using the spectrophotometer at $734 \mathrm{~nm}$. The ABTS scavenging capacity of the extract was compared with that of the standard (Vitamin C) solution and percentage inhibition calculated as:

$\%$ ABTS+ scavenging activity $=A b s$ (control)-Abs (sample) / x 100.

Where Abs (control) is the absorbance of ABTS radical + methanol, and Abs (sample) is the absorbance of ABTS radical + sample extract or standard. 
Determination of $\alpha$-amylase inhibition Alpha-amylase inhibition: Alpha-amylase inhibition was measured colorimetrically as described previously with slight modifications (Kazeem et al. [20]). Briefly, $15 \mu \mathrm{L}$ of cookie test sample was incubated with $5 \mu \mathrm{L}$ porcine pancreatin (1 mg mL $\mathrm{mL}^{-1}$ in $1 \times$ PBS buffer solution; prepared fresh and kept on ice) for 10 minutes at $37^{\circ} \mathrm{C}$ in a 96-well microtiter plate. The reaction was initiated by the addition of $20 \mu \mathrm{L}$ starch solution and allowed to proceed for 30 minutes at $37{ }^{\circ} \mathrm{C}$; then stopped by the addition of $10 \mu \mathrm{L} \mathrm{HCl}$ (1 M in distilled water) and $75 \mu \mathrm{L}$ iodine reagent and the absorbance was measured at $580 \mathrm{~nm}$. Acarbose $(500 \mu \mathrm{M}$ stock solution prepared in PBS) was included as a positive control, no enzyme and no substrate controls were included for each sample to account for the absorbance of the extracts. The percentage $\alpha$-amylase inhibition was calculated as:

$\% \alpha$-amylase inhibition= amylase activity of controlamylase activity of test sample $\times 100$ Amylase activity of control.

Where amylase activity $=$ A $580 \mathrm{~nm}$ without enzyme- A $580 \mathrm{~nm}$ with enzyme:

Ethics statement: The guidelines of the Declaration of Helsinki for human subjects were followed. Permission to conduct the study was granted by the University of Fort Hare Research Ethics Committee (UREC/OTU00121(Project)). Prior to the sensory evaluation study, all participants gave verbal informed consent (as it was only a routine tasting of cookies they were familiar with) and confidentiality was assured by using unique identification numbers instead of names for participants. Documents and data were accessible to the researchers only and stored in proper repositories.

Statistical analysis: All analyses were performed in triplicates and data expressed as mean \pm standard deviation. Excel spread sheets and one-way analysis of variance (ANOVA) was used as appropriate. Means were separated using Duncan's multiple range test, differences were significant at $P<0.05$. The student MINITAB 12 software was used for all statistical analyses.

\section{RESULTS}

Physical characteristics of cookies: Incorporation of the spice blend gave the cookies a slightly darker color compared to the control which was golden brown. Weight, diameter, height/thickness and texture of the cookies were also significantly $(P<0.05)$ affected (Table 2). The spice cookies had similar weights ranging from (14.58-15.92 g), which were significantly different from control (21.58 g). Only MC1 (5\% spice) cookies had similar diameter, thickness and spread ratio with the control, but MC2, MC3 and MC4 had similar physical characteristics. No significant difference $(P<0.05)$ was observed in the thickness of all the cookies.

Table 2: Physical characteristics of spice-blend and control cookies

\begin{tabular}{|l|l|l|l|l|}
\hline Cookies & Weight $(\mathrm{g})$ & Diameter $(\mathrm{mm})$ & \multicolumn{1}{l|}{ Thickness $(\mathrm{mm})$} & $4.24 \pm 0.31^{\mathrm{a}}$ \\
\hline Control & $21.58 \pm 1.16^{\mathrm{a}}$ & $5.00 \pm 0.31^{\mathrm{a}}$ & $1.18 \pm 0.04^{\mathrm{a}}$ & $4.41 \pm 0.22^{\mathrm{a}}$ \\
\hline MC1 & $15.83 \pm 0.47^{\mathrm{b}}$ & $5.08 \pm 0.24^{\mathrm{a}}$ & $1.15 \pm 0.00^{\mathrm{a}}$ & $3.72 \pm 0.04^{\mathrm{b}}$ \\
\hline MC2 & $15.91 \pm 0.42^{\mathrm{b}}$ & $4.38 \pm 0.04^{\mathrm{b}}$ & $1.18 \pm 0.00^{\mathrm{a}}$ & $3.55 \pm 0.04^{\mathrm{b}}$ \\
\hline MC3 & $14.58 \pm 0.92^{\mathrm{b}}$ & $4.15 \pm 0.00^{\mathrm{b}}$ & $1.17 \pm 0.01^{\mathrm{a}}$ & $3.49 \pm 0.02^{\mathrm{b}}$ \\
\hline MC4 & $15.5 \pm 0.20^{\mathrm{b}}$ & $4.14 \pm 0.00^{\mathrm{b}}$ & $1.18 \pm 0.01^{\mathrm{a}}$ & \\
\hline
\end{tabular}

Values are mean \pm standard deviation $(n=4)$. Means with different superscript letters within the same column differ significantly $(P<0.05)$. MC1-5\% spice-blend cookie; MC2-10\% spice-blend cookie; MC3-15\% spice-blend cookie; MC4-20\% spice-blend cookie 
Proximate content: The chemical composition of the cookies is presented in Table 3. No significant difference was observed in the moisture and crude protein of all the cookies, although control was slightly higher than the spice cookies. Ash content increased as the spiceblend increased and was lowest (1.60 \%) in control, but highest $(2.27 \%)$ in MC4. Crude fat content followed the same trend and ranged from $15.39 \%$ in control to
$18.63 \%$ in MC4. Crude fiber was lowest in $\operatorname{MC1}(6.48 \%)$ and highest in MC4 (11.47\%). Significant increase ( $P<$ 0.05) was observed for $\mathrm{Mg}, \mathrm{K}, \mathrm{Na}, \mathrm{P}$ and $\mathrm{Mn}$ of the cookies as the spice-blend increased, while there was no difference in the calcium, copper, zinc and iron contents. Energy values was lowest (419.23) in control cookies and highest in MC1 (451.52), but decreased as the spice increased.

Table 3: Proximate, energy and mineral composition of spice-blend and control cookies

\begin{tabular}{|c|c|c|c|c|c|}
\hline Indices & Control & MC1 & MC2 & MC3 & MC4 \\
\hline Moisture & $1.52 \pm 0.45^{\mathrm{a}}$ & $1.62 \pm 0.31^{\mathrm{a}}$ & $1.79 \pm 0.23^{a}$ & $1.51 \pm 0.11^{\mathrm{a}}$ & $1.21 \pm 0.45^{\mathrm{a}}$ \\
\hline Ash & $1.60 \pm 0.00^{a}$ & $1.92 \pm 0.03^{\mathrm{a}}$ & $2.03 \pm 0.02^{b}$ & $2.30 \pm 0.06^{b}$ & $2.27 \pm 0.04^{b}$ \\
\hline Fat & $15.39 \pm 0.12^{a}$ & $18.32 \pm 0.21^{b}$ & $18.40 \pm 0.42^{b}$ & $18.63 \pm 0.19^{b}$ & $18.74 \pm 0.05^{b}$ \\
\hline Crude fiber & $11.31 \pm 0.15^{a}$ & $6.48 \pm 1.31^{b}$ & $7.00 \pm 0.06^{b}$ & $8.27 \pm 0.46^{c}$ & $11.47 \pm 0.78^{a}$ \\
\hline Total protein & $11.52 \pm 0.14^{a}$ & $10.61 \pm 0.05^{b}$ & $10.70 \pm 0.08^{b}$ & $10.81 \pm 0.03^{b}$ & $10.98 \pm 0.02^{\mathrm{ab}}$ \\
\hline Total Carbohydrates & $58.66 \pm 0.17^{a}$ & $61.05 \pm 0.38^{b}$ & $60.08 \pm 0.16^{c}$ & $58.47 \pm 0.27^{a}$ & $55.33 \pm 0.27^{d}$ \\
\hline Energy (kcal $100 \mathrm{~g}^{-1}$ ) & $419.23^{a}$ & $451.52^{b}$ & $448.72^{\mathrm{C}}$ & $444.79^{\text {cd }}$ & $433.90^{\mathrm{e}}$ \\
\hline Calcium & $95.44 \pm 1.59^{a}$ & $93.50 \pm 3.76^{\mathrm{ab}}$ & $86.54 \pm 0.81^{c}$ & $89.349 \pm 0.09^{d}$ & $86.03 \pm 0.62^{c}$ \\
\hline Magnesium & $28.42 \pm 1.90^{a}$ & $29.47 \pm 0.92^{\mathrm{ab}}$ & $31.56 \pm 1.09^{c}$ & $37.56 \pm 1.05^{d}$ & $38.46 \pm 0.17^{\text {de }}$ \\
\hline Potassium & $151.30 \pm 1.70^{\mathrm{a}}$ & $196.19 \pm 3.67^{b}$ & $289.20 \pm 12.89^{c}$ & $367.55 \pm 8.53^{d}$ & $415.02 \pm 0.13^{e}$ \\
\hline Sodium & $310.74 \pm 5.48^{a}$ & $385.24 \pm 3.84^{b}$ & $375.72 \pm 2.17^{b c}$ & $393.94 \pm 0.43^{d}$ & $381.62 \pm 0.72^{\text {be }}$ \\
\hline Phosphorus & $274.18 \pm 3.28^{a}$ & $318.17 \pm 0.00^{b}$ & $307.50 \pm 0.72^{b}$ & $335.06 \pm 4.43^{c}$ & $320.88 \pm 0.44^{\mathrm{cd}}$ \\
\hline Zinc & $1.01 \pm 0.00^{\mathrm{a}}$ & $0.81 \pm 0.00^{a b}$ & $1.83 \pm 1.02^{a}$ & $0.81 \pm 0.00^{a b}$ & $0.80 \pm 0.00^{a b}$ \\
\hline Copper & $0.10 \pm 0.00^{a}$ & $0.08 \pm 0.00^{b}$ & $0.18 \pm 0.10^{a}$ & $0.08 \pm 9.07^{b}$ & $0.08 \pm 0.00^{b}$ \\
\hline Manganese & $0.50 \pm 0.09^{a}$ & $1.01 \pm 0.00^{b}$ & $1.93 \pm 0.10^{b}$ & $2.94 \pm 0.09^{c}$ & $3.23 \pm 0.01^{d}$ \\
\hline Iron & $1.42 \pm 0.20^{a}$ & $1.11 \pm 0.30^{\mathrm{a}}$ & $0.91 \pm 0.09^{a b}$ & $1.01 \pm 0.20^{a}$ & $0.91 \pm 0.10^{a b}$ \\
\hline
\end{tabular}

*Values in the same row with different superscript are significantly different $(P \leq 0.05)$. Means are \pm standard deviations of triplicate samples. Key: Control= 100\% wheat flour cookies; MC1=95\% wheat flour + 5\% Spice-blend cookies; MC2 = $90 \%$ wheat flour $+10 \%$ Spice-blend cookies; MC3 = 85\% wheat flour $+15 \%$ Spice-blend cookies; MC4 = 80\% wheat flour + $20 \%$ Spice-blend cookies.

Sensory attributes: The sensory properties of control of the spice-blend fortified cookies evaluated using ninepoint hedonic scale are shown in Figure 1. No statistical difference was observed in the color and texture of all the cookies, but in flavor and taste. Interestingly, MC1 scored best with regards to flavor followed by control, 
while MC4 scored the least. In terms of taste, the cookies were ranked in order of preference as: Control>MC1 $>M C 2>M C 3>M C 4$. No significant difference between control and MC1 was observed in overall acceptability, but both were significantly different from the other cookies. Of the spice enriched products, the MC1 (5\% fortification) was the closest to the control.

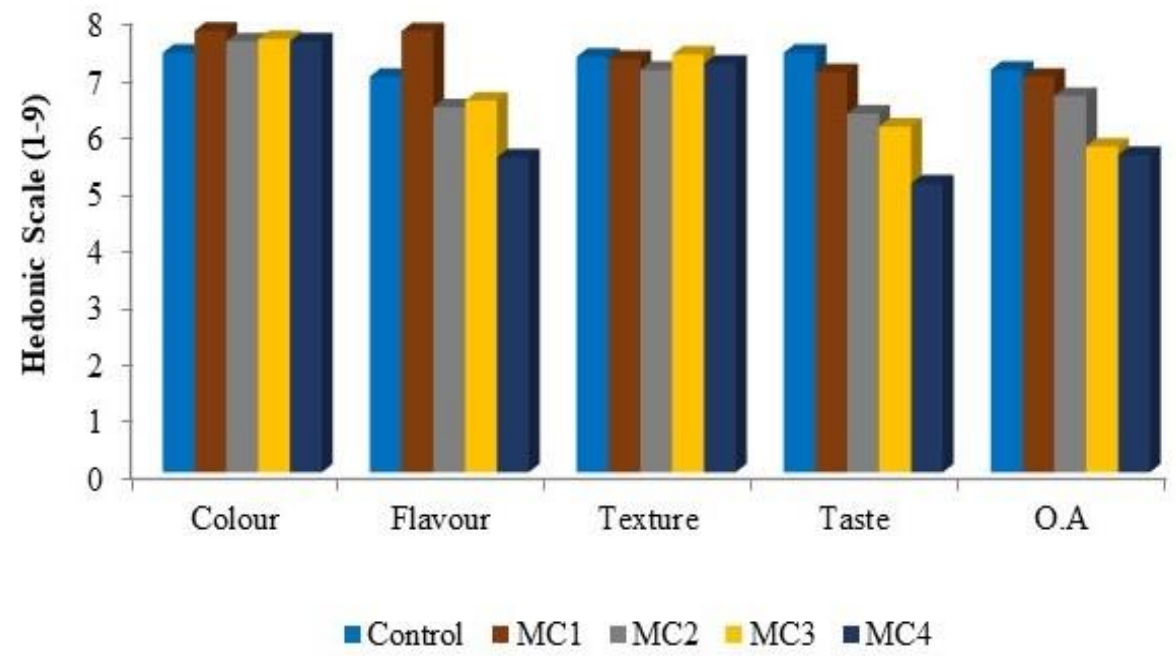

Figure 1: Sensory attributes of spice-blend and control cookies

*Values in are Means \pm standard deviations of triplicate samples ( $P \leq 0.05$ ). Key: Control= 100\% wheat flour cookies; MC1= 95\% wheat flour $+5 \%$ Spice-blend cookies; MC2 = 90\% wheat flour $+10 \%$ Spice-blend cookies; MC3 = 85\% wheat flour $+15 \%$ Spice-blend cookies; MC4 $=80 \%$ wheat flour $+20 \%$ Spice-blend cookies

Total phenolic content (TPC) and antioxidant properties of spice-blend and control cookies: The total phenolic content of spice-blend and control cookies is illustrated in Figure 2. The effect of supplementation with the spice blend on the cookies did not follow a particular pattern, but the MC1 cookies showed the highest phenolic content (5.33) followed by the MC4, MC2 and MC3.

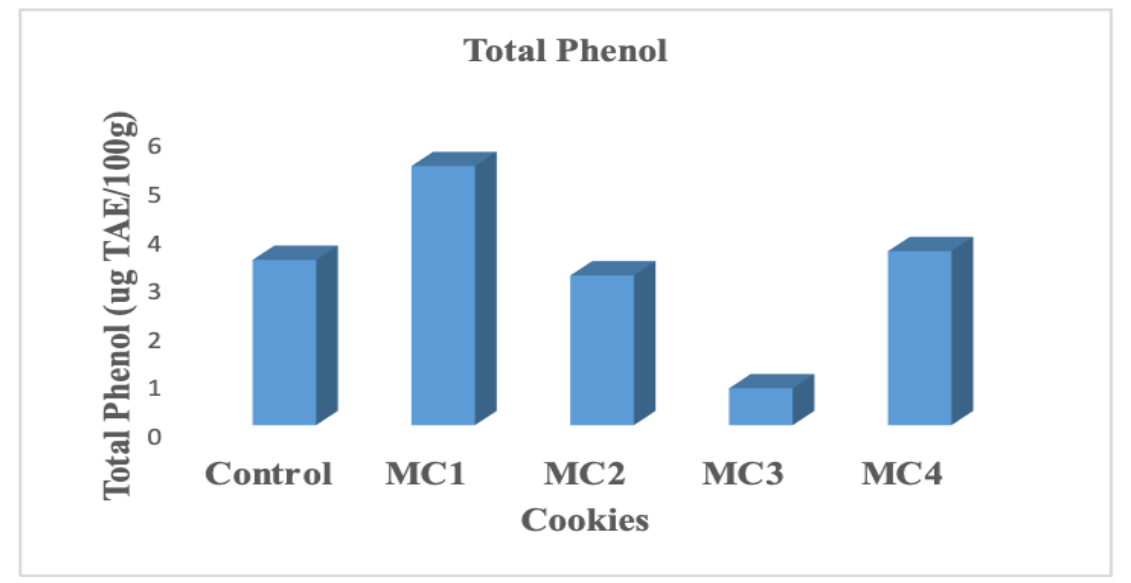

Figure 2: Total phenolic content (TPC, ug TAE/100g) of spice-blend and control cookies *Values in are Means \pm standard deviations of triplicate samples ( $P \leq 0.05$ ). Key: Control= $100 \%$ wheat flour cookies; MC1 $=95 \%$ wheat flour $+5 \%$ Spice-blend cookies; MC2 = 90\% wheat flour $+10 \%$ Spice-blend cookies; MC3 = 85\% wheat flour $+15 \%$ Spice-blend cookies; MC4 = 80\% wheat flour $+20 \%$ Spice-blend cookies. (TPC ( $\mu$ TAE/100g) 
Antioxidant activities: Antioxidant activities of the cookie samples determined using DPPH and ABTS radical scavenging models are shown in Figure 3.

ABTS radical scavenging capacity (Figure $3 a$ ) of all the cookies increased with concentration and was in the order: Vitamin $\mathrm{C}>\mathrm{MC} 4>$ Control $>\mathrm{MC} 3>\mathrm{MC} 2>\mathrm{MC} 1$. Among the spice-blend cookies, MC4 exhibited the highest (62.45\%) $\mathrm{ABTS}^{+}$scavenging property as confirmed by the $\mathrm{IC}_{50}$ values (Table 4).

With regards to DPPH radical scavenging (Figure 3b), the same concentration dependent trend was observed, MC4 exhibited the highest $\mathrm{DPPH}^{+}$scavenging property followed by MC2 with MC3 showing the least activity.

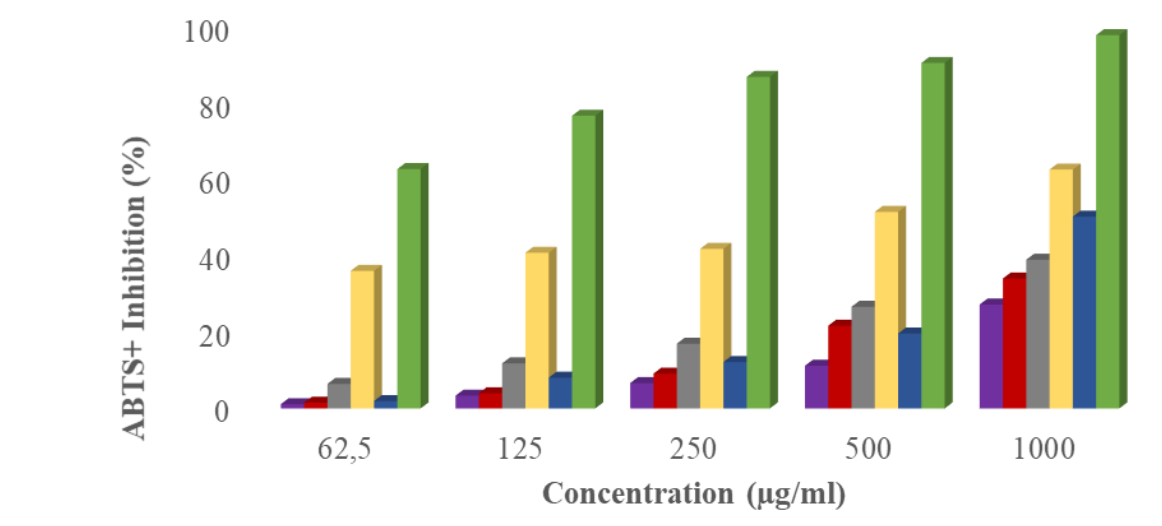

a

$\square \mathrm{MC1} \square \mathrm{MC2} \square \mathrm{MC3} \square \mathrm{MC4} \square$ Control $\square$ Vitamin C

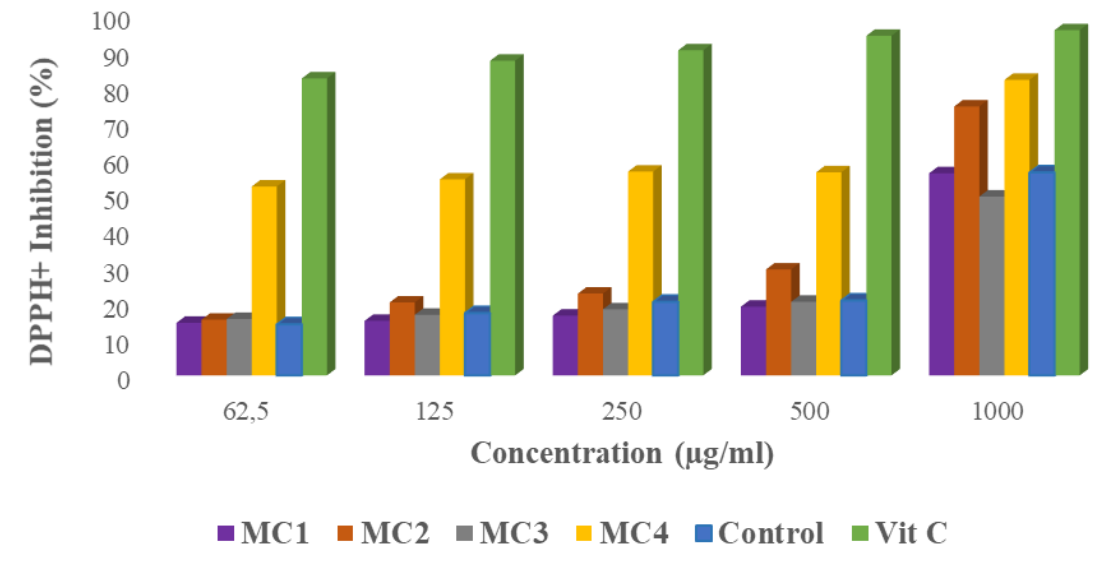

Figure 3: Free radical scavenging capacities (\%) of spice-blend and control cookies on a: $\mathrm{ABTS}^{+}$and b: $\mathrm{DPPH}^{+}$

*Values in are Means \pm standard deviations of triplicate samples $(P \leq 0.05)$. Key: Control=100\% wheat flour cookies; $M C 1=95 \%$ wheat flour $+5 \%$ Spice-blend cookies; MC2 = 90\% wheat flour + 10\% Spice-blend cookies; MC3 = 85\% wheat flour + 15\% Spice-blend cookies; MC4 $=80 \%$ wheat flour $+20 \%$ Spice-blend cookies

Alpha-amylase inhibition: Alpha-amylase activities of the cookies are presented in Figure 4. The cookies exhibited moderate alpha-amylase inhibition even higher or equipotent with the standard (acarbose) in a concentration dependent manner.
The activity was in the order: MC4>MC3 $>$ MC1>Control>Acarbose $>M C 2$. ThelC 50 values were 5.01 and 12.33, for MC4 and acarbose (antidiabetic drug used as standard reference) respectively. 


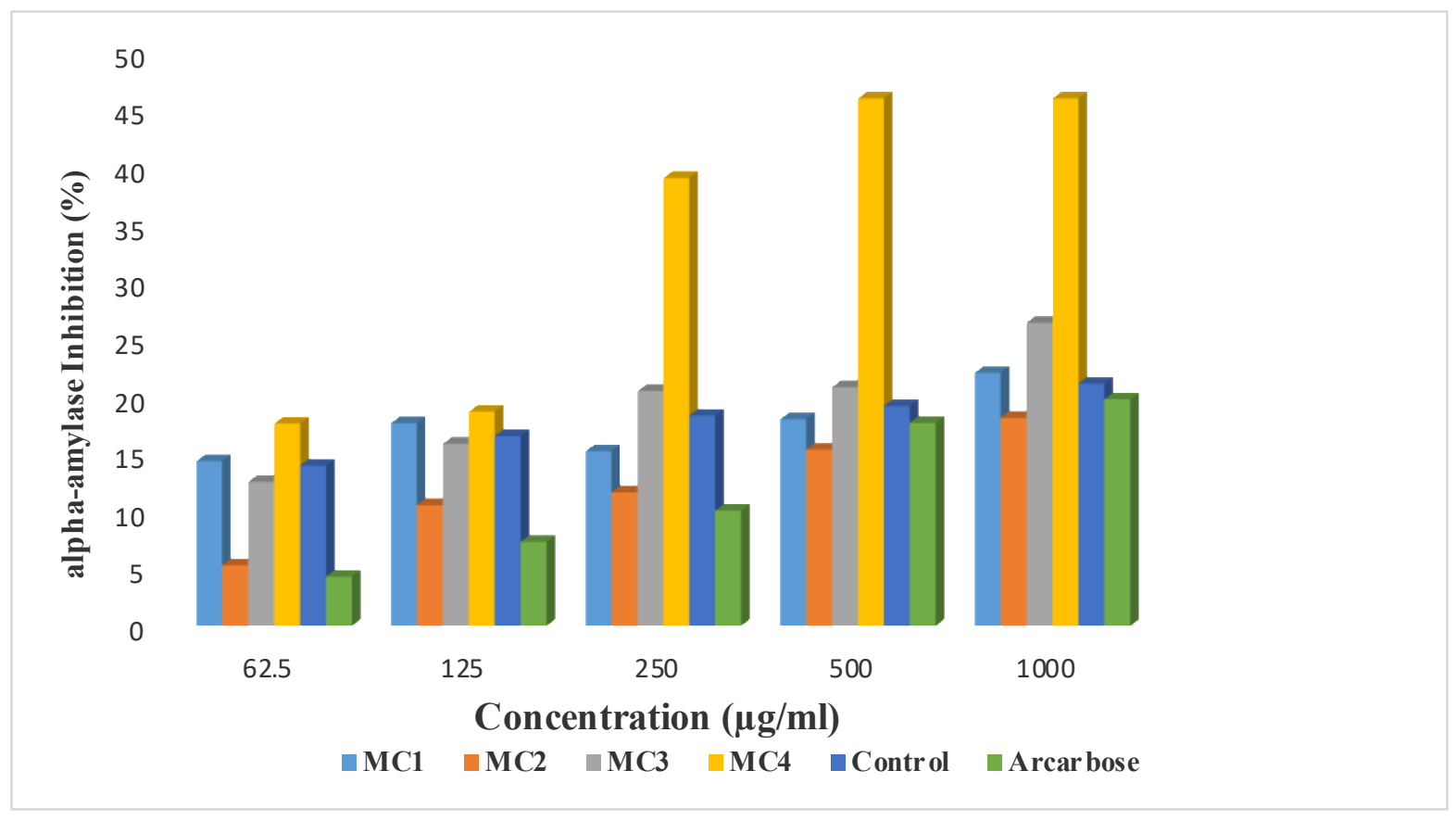

Figure 4: Inhibitory effects of cookies extracts at different concentrations against $\alpha$-amylase.

*Values in are Means \pm standard deviations of triplicate samples $(P \leq 0.05)$. Key: Control=100\% wheat flour cookies; MC1=95\% wheat flour $+5 \%$ Spice-blend cookies; MC2 = 90\% wheat flour + 10\% Spice-blend cookies; MC3 = 85\% wheat flour + 15\% Spice-blend cookies; MC4 $=80 \%$ wheat flour $+20 \%$ Spice-blend cookies; Acarbose $=$ positive control

Table 4: IC 50 values for ABTS, DPPH and $\alpha$-Amylase inhibitory effects of the cookies and standards

\begin{tabular}{|c|c|c|c|}
\hline Cookies/Standards & \multicolumn{2}{|c|}{ ABTS } & \multicolumn{2}{c|}{ DPPH } & a-Amylase \\
\hline MC1 & 9.79 & 5.9477 & 15.49 \\
\hline MC2 & 7.35 & 4.3667 & 12.52 \\
\hline MC3 & 6.75 & 6.5977 & 5.01 \\
\hline MC4 & 3.59 & 5.6238 & 22.19 \\
\hline Control & 5.93 & 2.3 & - \\
\hline Vitamin C & -0.9 & 8.8875 & 12.33 \\
\hline Arcabose & - & - & \\
\hline
\end{tabular}

\section{DISCUSSION}

The weight, thickness and spread ratio of the cookies were consistent with previous reports for fortified/composite cookies [21-25].

The moisture content of the spice-blend cookies which decreased with increasing concentration of spice incorporation, suggests that the materials for the fortified cookies are high in dry solids with greater emulsifying characteristics or water holding capacity than wheat flour [26-27]. Low moisture content of the cookies can prevent physical damage, lose of crispiness and spoilage caused by microorganisms such as mold. The slightly higher protein content of control cookies compared to the spice-blend cookies could be attributed 
to the fact that control cookies used $100 \%$ wheat flour which has gluten, whereas substitutions from 5-20\% with spice-blend respectively, reduced the amount of flour used for formulation of spice-blend cookies. This is similar to the reports of Hasrini et al. [27] for cookies produced from modified cassava flour (Mocaf) enriched with rich nutrition vegetable powder.

Inclusion of the spice-blend improved the fat, ash and fiber contents of the cookies in a dose-responsive pattern as the spice-blend increased. The crude fat content of control cookies was below that of the spiceblend cookies. The higher crude fat of the spice cookies could have come from the initial content of the spice materials used. Higher ash content is indicative of higher mineral content of the spice-blend cookies, which was reflected in the rich and high quantity of minerals. The increase in $\mathrm{Mg}, \mathrm{K}, \mathrm{P}$ and stability of $\mathrm{Fe}, \mathrm{Ca}, \mathrm{Zn}$ and $\mathrm{Cu}$ are indications that the cookies could support the daily requirements of these micronutrients in the diet. These observations agree with Macías et al. [28] who fortified cookies with mesquite flour.

Foods with high fiber content are advantageous for the wellbeing of the gut and whole human health, including lowering of cholesterol levels, blood sugar control, improved digestion and preventing colon cancer [29-31]. The fiber content of the cookies could therefore support the quality and daily requirements for dietary fiber.

The carbohydrate content of the control cookies was not significantly different, though the control cookies had slightly higher content. Carbohydrates are sources of energy needed by the body for metabolism, though the main source of carbohydrates in this case comes from the wheat flour. The energy values of the fortified cookies agree with previous reports and suggest that the cookies could add up to $30 \%$ of the daily caloric needs of the diet [32].

Sensory evaluation report of darker color for the spice-blend cookies could be as a result of decomposed or transformed polyphenols or carotenoids. Generally, the fortified cookies were highly accepted, because the lowest overall acceptability score was 5.58 for MC4 (20\% spice-blend). However, the MC1 cookies (5\% spice-blend) had the highest overall acceptability score. This is similar to the report of Costa de Camargo et al. [33] that $2.5 \%$ peanut skin-fortified cookies and cookies made with defatted maize germ flour [34] were well accepted. The other spice-blend cookies were however not well accepted because increasing the quantity of the spice to 10,15 and $20 \%$ resulted in excessive spiciness ('hotness'). The low phenolic content of the cookies could be as a result of thermal degradation and transformation which occurred during the baking process. The reduced TPC reported here agrees with previous studies that baking always leads to a general decrease in TPC, even at $150{ }^{\circ} \mathrm{C}$, although some residual phenolics are left when baking is done at this temperature $[17,34]$. The low TPC of the cookies could account for the reduced antioxidant activity as phenolic content often correlate with antioxidant activity. The observed ABTS and DPPH radicals scavenging activities of the cookies were therefore, most likely enhanced by other components, such as $\beta$-carotene and ferulic acid which can contribute to antioxidant activities; [35] or Maillard reactions, since antioxidant activity due to nonenzymic browning and Maillard reactions have been reported in cookies [36]. Dietary antioxidants especially polyphenols have great therapeutic potential and help in maintaining oxidative stability of foods.

The outcome of this study agrees with previous studies on antioxidant properties of cookies fortified with foxtail millet and ginger powder, mushroom flour, minor millets, peanut skins, or oat-buckwheat dough and cookies with added spices or herbs [17,24$25,33,37]$.

Alpha-amylase is one of the vital enzymes involved in the breakdown of starch to glucose, thus, its inhibition could be effective in maintaining glucose homeostasis for diabetes since only glucose is readily 
absorbed by the intestinal lumen. Alpha-amylase inhibition is therefore useful in evaluating extracts and foods for their capacity to modify post-prandial glycaemic response.

Acarbose has the capacity to delay glucose absorption by inhibiting the upper gastrointestinal glucosidases resulting in reduced postprandial hyperglycemia in a dose-dependent manner; thus, it is a common drug for treating patients with type 2 diabetes, though with negative side effects. Therefore, inhibitory effects of the cookies against $\alpha$-amylase were evaluated using acarbose as a positive control. The moderate $\alpha$ amylase inhibition demonstrated by the spice-blend cookies implies that the cookies can support the dietary management of postprandial hyperglycemia. According to Kamruzzaman et al. [38] a nutrient preload (consumption of a small amount of macronutrient at a fixed interval (30-60 $\mathrm{min}$ ) before a meal) could reduce postprandial glycemic excursion. This is consistent and agrees with reports from other studies that foods, plant or spice extracts that possess mild $\alpha$-amylase inhibition could be suitable alternatives for drugs currently in use for inhibiting $\alpha$-glucosidase and $\alpha$-amylase which have the disadvantage of negative side effects like bloating, diarrhea and flatulence [38-40].

\section{CONCLUSION}

Fortification with the spice blend not only improved nutritional quality, but also enhanced bioactivity characteristics as evidenced by the antioxidant and alpha-amylase inhibitory activities of the cookies. In terms of physical attributes and overall acceptability, MC1 (5\% spice blend) was the closest to the control. Although MC4, MC3 and MC2 showed higher antioxidant and alpha-amylase activities, they were organoleptically unacceptable because they were too spicy ('hot'). These results as shown in the proximal, mineral and energy values, indicate that cookies fortified with $5 \%$ spice-blend apart from being good sources of nutrients; also possess antioxidant and $\alpha$ - amylase inhibition activities and therefore has potential as a therapeutic healthy snack that could prevent malnutrition and hyperglycemia in type 2 diabetes.

Overall, the findings support dietary polyphenols from spices as functional food ingredients with health benefits.

Future Perspectives: These results indicate that cookies fortified with $5 \%$ spice-blend are good sources of nutrients, possess antioxidant and $\alpha$-amylase inhibition activities and has potential as a therapeutic healthy snack that could prevent malnutrition and hyperglycemia in type 2 diabetes. Further studies including use of natural sweeteners and clinical evaluations are therefore necessary and in view.

Conflict of Interest: The authors declare that the research was conducted in the absence of any commercial or financial relationships that could be construed as a potential conflict of interest.

Abbreviations: MC1: $95 \%$ wheat flour $+5 \%$ Spice-blend cookies, MC2: $90 \%$ wheat flour $+10 \%$ Spice-blend cookies, MC3: 85\% wheat flour $+15 \%$ Spice-blend cookies, MC4: $80 \%$ wheat flour $+20 \%$ Spice-blend cookies, DPPH+: 2, 2-diphenyl-1-picrylhydrazyl radical, ABTS+: 2,2-azinobis-3-ethylbenzo-thiazoline-6-sulfonate radical, TPC: Total phenolic content

Author Contributions: GA: conceptualization. GA and AJ: methodology and funding acquisition. $G A$ and $A J$ : validation and writing-review and editing. $G A$ and $A J$ : formal analysis, investigation and data curation. GA: writing-original draft preparation. Both authors read and agreed to the submitted manuscript.

Funding: This work was supported by the South Africa National Research Foundation: Research and Innovation Support and Advancement (NRF: RISA) CSURG: Grant No: 121264. 


\section{REFERENCES}

1. Wani SH, Gull A, Allaie F, Safapuri TA. Effects of incorporation of whey protein concentrate on physicochemical, texture, and microbial evaluation of developed cookies. Cogent Food Agric. 2015; 1:1. https://DOI.org/10.1080/23311932.2015.1092406

2. Pratima A, Yadav MC. Effect of incorporation of liquid dairy by-products on chemical characteristics of soy-fortified biscuits. J Food Sci Technol (Mysore). 2000; 37(2):158-61.

3. Arshad MU, Anjum FM, Zahoor T. Nutritional assessment of cookies supplemented with defatted wheat germ. Food Chem. 2007; 102:123-128.

https://doi.org/https://doi.org/10.1016/j.foodchem.2006.04.0 $\underline{40}$

4. Dzoyem JP, Tchuenguem RT, Kuiate JR, Teke GN, Kechia FA, Kuete $\mathrm{V}$. In vitro and in vivo antifungal activities of selected Cameroonian dietary spices. BMC Complemen Altern Med. 2014; 14:58. https://doi.org/10.1186/1472-6882-14-58

5. Gottardi D, Bukvicki D, Prasad S, Tyagi AK. Beneficial Effects of Spices in Food Preservation and Safety. Front Microbiol. 2016; 7:1394. https://doi.org/10.3389/fmicb.2016.01394

6. Yashin A, Yashin Y, Xia X, Nemzer B. Antioxidant Activity of Spices and Their Impact on Human Health: A Review. Antioxidant (Basel). 2017; 6(3):70. https://doi.org/10.3390/antiox6030070

7. Sasikumar JM, Erba O, Egigu MC. In vitro antioxidant activity and polyphenolic content of commonly used spices from Ethiopia. Heliyon. 2020; 6(9):e05027. https://doi.org/10.1016/j.heliyon.2020.e05027

8. Zarei A, Vaezi G, Malekirad AA, Abdollahi M. Effects of ethanol extract of Salvia hydrangea on hepatic and renal functions of streptozotocin-induced diabetic rats. Avicenna J Phytomed. 2015; 5(2):138-147.

9. Otunola GA, Afolayan AJ. Evaluation of the Polyphenolic Contents and Antioxidant Properties of Aqueous Extracts of Garlic, Ginger, Cayenne Pepper and their Mixture. J Appl Bot Food Qual. 2013; 86 (1):66-70. https://DOI.org/10.5073/JABFQ.2013.086.010

10. Otunola GA, Afolayan AJ. Antidiabetic effect of combined spices of Allium sativum, Zingiber officinale and Capsicum frutescens in alloxan-induced diabetic rats. Front Life Sci. 2015; 8 (4):314- 323. https://doi.org/10.1080/21553769.2015.1053628

11. Nair SS, Kavrekar V, Mishra A. In vitro studies on alpha amylase and alpha glucosidase inhibitory activities of selected plant extracts. Eur J Experimentl Biol. 2013; 3(1):128-132.
12. Navas-Carretero S, Abete I, Zulet M.A, Martínez JA. Chronologically scheduled snacking with high-protein products within the habitual diet in type-2 diabetes patients leads to a fat mass loss: a longitudinal study. BMC Nutr J. 2011; 10. 74 https://doi.org/10.1186/1475-2891-10-74

13. Heller S, Worona L, Consuelo A. Nutritional therapy for glycogen storage diseases. I Pediatric Gastroenterol Nutr. 2008; 47: 15-21.

https://doi.org/10.1097/MPG.0b013e3181818ea5

14. McWatters KH, Ouedraogo JB, Resurreccion AVA, Hung Y-C, Phillips RD. Physical and sensory characteristics of sugar cookies containing mixtures of wheat, fonio (Digitaria exilis) and cowpea (Vigna unguiculata) flours. Intern J Food Sci Technol. 2003;. 38: 403-410. https://doi.org/10.1046/i.13652621.2003.00716.x

15. Agri Laboratory Association of South Africa (AgriLASA). Method no. 6.1.1 for feeds and plants. In 'Agrilasa Handbook Feeds Plant Anal. 2007; vol. 1'. 2nd edn. (Eds P Palic, AS Claasens, J Collier, A Loock, D Hattingh) (Agri Laboratory Association of South Africa: Pretoria).

16. Association of Analytical Chemists (AOAC). Official Methods of Analysis. 19th Edition, Washington DC.(2012) 121-130.

17. Starowicz M, Arpaci S, Topolska J, Wronkowska M. Phytochemicals and Antioxidant Activity in Oat-Buckwheat Dough and Cookies with Added Spices or Herbs. Molecule. 2021; 26(8):2267. https://doi.org/10.3390/molecules26082267

18. Carmona-Jiménez Y, García-Moreno MV, García-Barroso C. Effect of Drying on the Phenolic Content and Antioxidant Activity of Red Grape Pomace. Plant Food Human Nutr. 2018;73(1):74-81. https://doi.org/10.1007/s11130-018-0658-1

19. Thaipong K, Boonprakob U, Crosby K. Comparison of ABTS, DPPH, FRAP, and ORAC assays for estimating antioxidant activity from guava fruit extracts. J Food Comp Anal. 2006; 19:669-675.https://doi.org/10.1016/i.fca.2006.01.003

20. Kazeem MI, Adamson JO, Ogunwande IA. Modes of inhibition of $\alpha$-amylase and $\alpha$-glucosidase by aqueous extract of Morinda lucida Benth leaf. BioMed Res Intern. 2013; 2013:527570. https://doi.org/10.1155/2013/527570

21. Srivastava S, Genitha TR, Yadav V. Preparation and quality evaluation of flour and biscuit from sweet potato. J Food Process Technol. 2012; 3(192):2 https://doi.org/10.4172/2157-7110.1000192 
22. Deepali SK, Talib MI, Parate VR, Shrirame V. Development of Lemongrass flavoured high nutrient cookies by fortification of flaxseed and poppy seed flour. Intern J Eng Res Technol 2015; 4(10) https://dx.doi.org/10.17577/IKERTV4IS100248

23. Cheng YF, Bhat R. Functional, physicochemical and sensory properties of novel cookies produced by utilizing underutilized jering (Pithecellobium jiringa Jack.) legume flour. Food Biosci. 2016;1(14):54-61. https://doi.org/10.1016/j.fbio.2016.03.002

24. Sharma P, Gujral HS. Cookie making behavior of wheat-barley flour blends and effects on antioxidant properties. LWT-Food Sci Technol. 2014;55(1):301-307.

25. Chen C, Han Y, Li S, Wang R, Tao C. Nutritional, antioxidant, and quality characteristics of novel cookies enriched with mushroom (Cordyceps militaris) flour. CyTA -J Food. 2021; 19 (1) $137-145$ https://DOI.org/10.1080/19476337.2020.1864021

26. Ghoshal G, Kaushik P. Development of soymeal fortified cookies to combat malnutrition. Legume Sci. 2020; 2:e43. https://doi.org/10.1002/leg3.43

27. Hasrini R, Aviana T, Khoiriyah A. Fortification of Modified Cassava Flour (Mocaf) Cookies with Rich Nutrition Vegetable Powder. E3S Web of Conferences.(2021) 232:03009 .https://DOI.org/10.1051/e3sconf/202123203009

28. Macías S, López C, Costa K, Generoso S. Sensory Quality and Acceptability in Mesquite Flour Complemented- and MineralFortified Cookies Sensory Evaluation In Fortified Cookies. Intern J New Technol Res. 2016; 2(7): 109-114

29. Soliman GA. Dietary Fiber, Atherosclerosis, and Cardiovascular Disease. Nutrient. 2019; 11(5):1155. https://doi.org/10.3390/nu11051155

30. Sun NX, Tong LT, Liang TT, Wang LL, Liu LY, Zhou XR, Zhou SM. Effect of oat and tartary buckwheat-based food on cholesterol-lowering and gut microbiota in hypercholesterolemic hamsters. J Oleo Sci. 2019;:ess18221. https://doi.org/10.5650/jos.ess18221

31. Felson S. Types of Fiber and Their Health Benefits. 2020; [https://www.webmd.com/diet/compare-dietaryfibers] Retrieved September 20, 2021.

32. Ahmed MSH, Hussein MM, Salama MF, Hamed IM, Fouda KA, Mohamed RS. Formulation and Evaluation of Functional Cookies for Improving Health of Primary School Children. Pakistan J Biol Sci. 2018; 21: 401-408. https://DOI.org./10.3923/pjbs.2018.401.408
33. De Camargo AC, Vidal CM, Canniatti-Brazaca SG, Shahidi F. Fortification of cookies with peanut skins: effects on the composition, polyphenols, antioxidant properties, and sensory quality. J Agric Food Chem. 2014; 62(46):11228-35. https://doi.org/10.1021/if503625p

34. Blanch GP, Ruiz del Castillo ML. Effect of Baking Temperature on the Phenolic Content and Antioxidant Activity of Black Corn (Zea mays L.) Bread. Food. 2021; 10(6):1202. https://doi.org/10.3390/foods10061202

35. Srinivason M, Sudheer AR. Ferulic acid: Therapeutic potential through its antioxidant activity. J Clin Biochem Nutr. 2007; 40: 92-100. https://doi.org/10.3164/jcbn.40.92

36. Zilic S, Kocadagli T, Vancetovic J, Gökmen V. Effects of baking conditions and dough formualtions on phenolic compounds stability, antioxidant capacity and color of cookies made from anthocyanin-rich corn flour. LWT-Food Sci Technol. 2016; 65: 597-603. https://doi.org/10.1016/j.lwt.2015.08.057

37. Marak NR, Malemnganbi CC, Marak CR, Mishra LK. Functional and antioxidant properties of cookies incorporated with foxtail millet and ginger powder. J Food Sci Technol. 2019; 56(11):5087-5096 https://doi.org/10.1007/s13197-019-03981-6

38. Kamruzzaman M, Horowitz M, Jones KL, Marathe CS. GutBased Strategies to Reduce Postprandial Glycaemia in Type 2 Diabetes. Front Endocrinol. 2021; 12:322. https://doi.org/10.3389/fendo.2021.661877

39. Oboh G, Akinyemi AJ, Ademiluyi AO, Adefegha SA. Inhibitory effects of aqueous extract of two varieties of ginger on some key enzymes linked to type-2 diabetes in vitro. J Food Nutr Res. 2010; 49:14-20.

40. Adefegha SA, Olasehinde TA, Oboh G. Pasting alters glycemic index, antioxidant activities, and starch-hydrolyzing enzyme inhibitory properties of whole wheat flour. Food Sci Nutr. 2018; 6:1591-1600. https://doi.org/10.1002/fsn3.711

41. Li K, Yao F, Xue Q, Fan H, Yang L, Li X, Sun L, Liu Y. Inhibitory effects against $\alpha$-glucosidase and $\alpha$-amylase of the flavonoidsrich extract from Scutellaria baicalensis shoots and interpretation of structure-activity relationship of its eight flavonoids by a refined assign-score method. BMC Chem Central J. 2018; 12(1):82. https://doi.org/10.1186/s13065-018-0445-y 